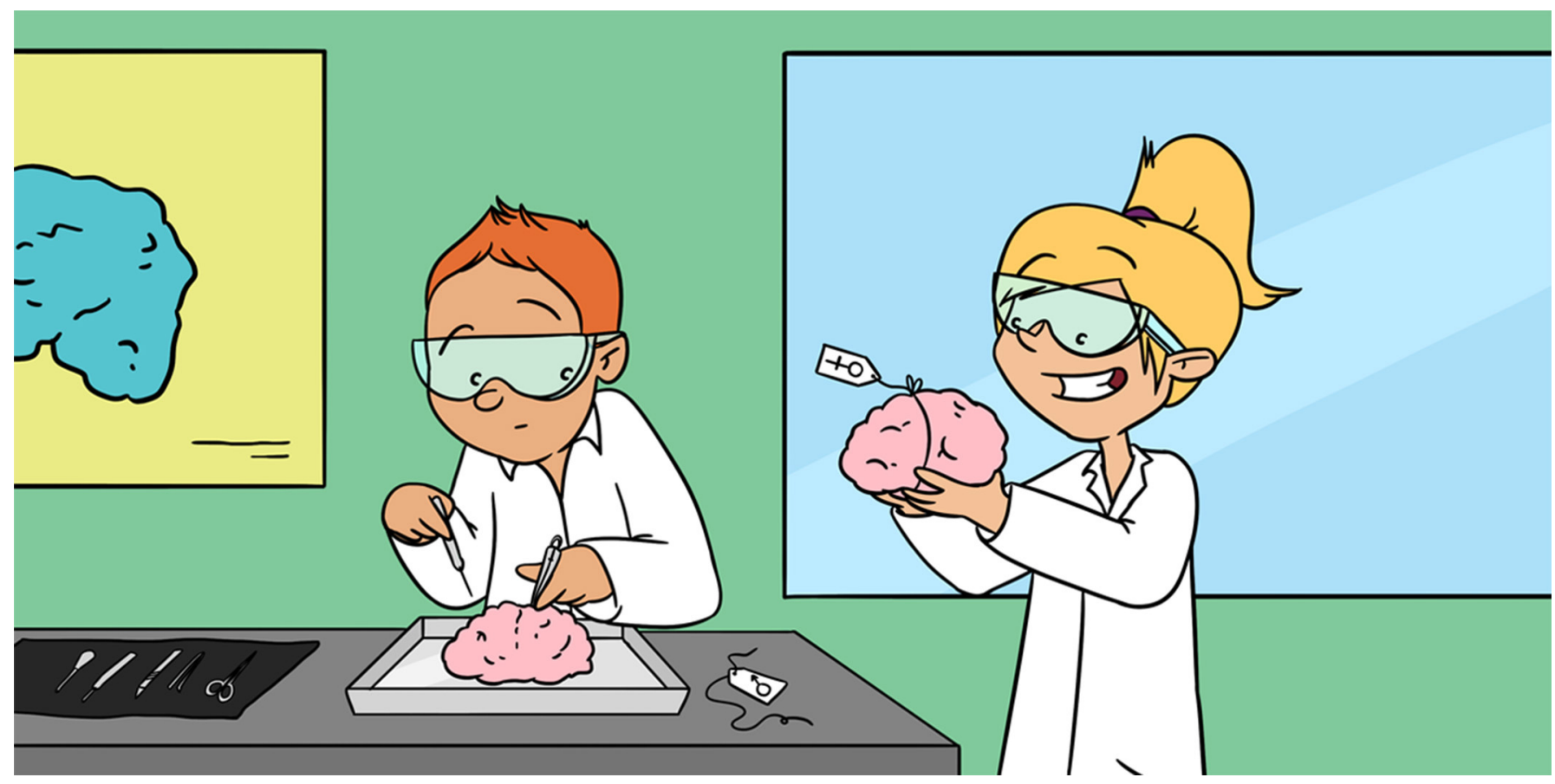

\title{
WHY NEUROSCIENCE NEEDS GIRLS: GENDER DIVERSITY DRIVES SCIENTIFIC DISCOVERY
}

\section{Emily G. Jacobs ${ }^{1,2 *}$}

${ }^{1}$ Department of Psychological and Brain Sciences, University of California, Santa Barbara, Santa Barbara, CA, United States ${ }^{2}$ Neuroscience Research Institute, University of California, Santa Barbara, Santa Barbara, CA, United States

\section{YOUNG REVIEWERS:}

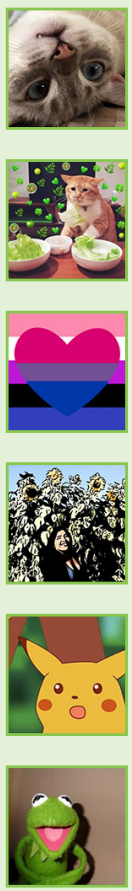

CASSIDY

AGE: 13

EMILY

AGE: 13

LEE

AGE: 18

SARAHI

AGE: 16

SAWYER

AGE: 13

ZAHRA

AGE: 13
Women make up half of the world's population. Yet for half a century, neuroscience has largely overlooked women's health. Scientists who conduct research in animals primarily study males and exclude females, a research habit that greatly reduces the potential impact of our scientific discoveries. Animal research helps scientists develop drugs and treatments for brain disorders, so the sex bias in animal research risks the lives of women worldwide. Thanks to the advocacy work of female scientists and doctors, this research practice is starting to change. This article talks about hurdles girls face in science and why achieving diversity in science is more than just the "right thing to do." Diversity in science makes science better and helps make sure our research benefits men and women.

\section{THE MOONSHOT OF OUR GENERATION}

At first glance, the human brain looks pretty unremarkable, like a three-pound squishy walnut (Figure 1). But look closer, at the 
Figure 1

The human brain contains $>85$ billion neurons that, together, give rise to nearly everything we do as humans-thinking, seeing, smelling, moving, sleeping, even breathing. It is no wonder there are more cells in a single human brain than there are stars in the entire Milky Way Galaxy.

\section{NEUROSCIENTISTS}

A neuroscientist is a scientist who studies the brain.

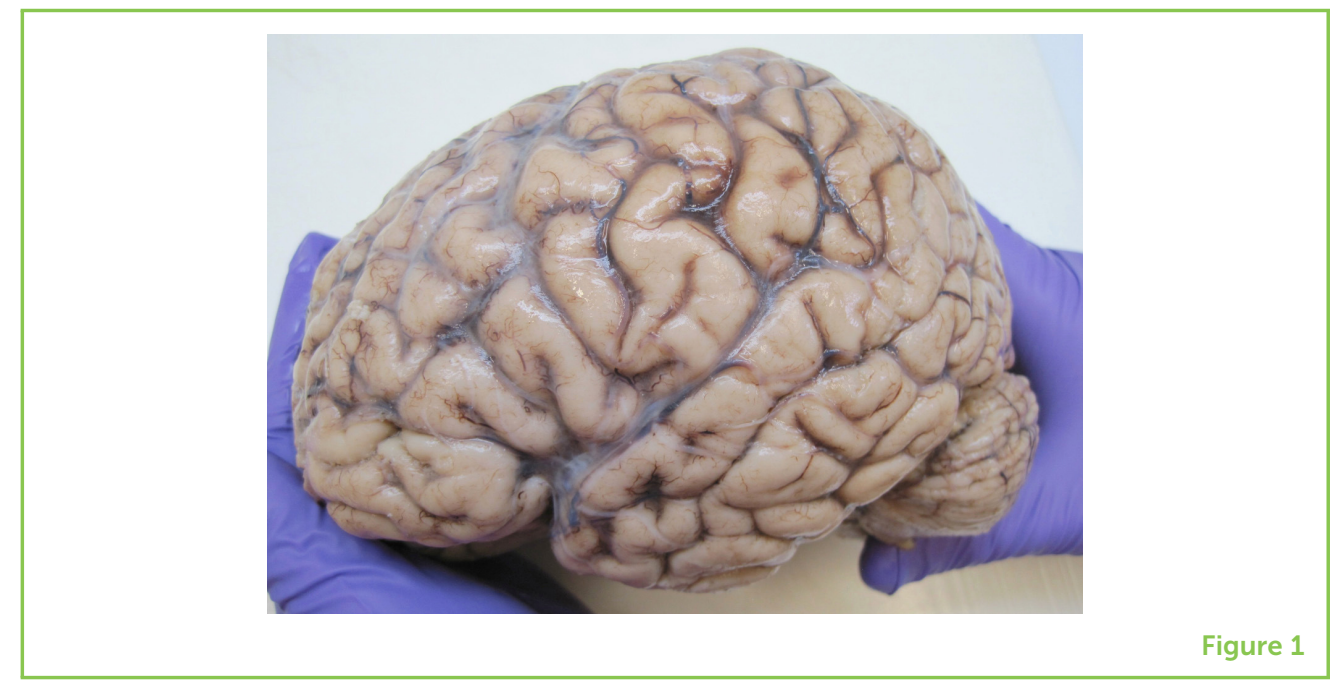

microscopic level, and you will find over 85 billion neurons wired together into precise circuits. These neural circuits are responsible for an incredible range of complex behaviors. That three-pound squishy walnut is capable of writing an opera, building civilizations, and inventing tools that allow us to see into the deepest corners of space. Even more amazing, the human brain can invent tools to see and study itself.

Fifty years ago, in 1969, scientists landed a human on the moon. This was the most amazing accomplishment of that generation. In 2013, President Obama said that understanding how the brain works is one of the greatest scientific challenges of our time. It is the moonshot of our generation. Fifty years from now, in 2069, what discoveries will scientists make about the brain? Around the world, neuroscientists are trying to understand how the healthy brain gives rise to the mind and what goes wrong in brain disorders like Alzheimer's, depression, and schizophrenia. If we have any hope of meeting these challenges, we need the best minds at the table and in the laboratory, inventing radically new ways of seeing, probing, and understanding the brain.

\section{WHO GETS TO BE A SCIENTIST?}

A century ago, professional scientists were mostly men. Women were working hard just to gain equal access to education. A famous photograph taken in 1927 shows a meeting of the world's top scientists of that era (Figure 2). The picture shows scientific super-stars like Albert Einstein and Erwin Schrodinger, whose research shaped the world we live in. Of the 29 attendees, 28 were men of European origin. Marie Curie, a pioneering scientist who worked in physics and chemistry and won two Nobel prizes, was the only woman in attendance. Although these scientists compiled an incredible list of scientific achievements, one can only imagine how much more 
Figure 2

Attendees of the 1927 Solvay Conference in Belgium, a prestigious meeting of scientists that included Albert Einstein, Erwin Schrodinger, and Marie Curie (front row, second from left). Of the 29 attendees, all but one were men of European origin.

\section{IMPLICIT BIAS}

Implicit bias refers to the unconscious thoughts and feelings we have about other people. For example, sometimes we make assumptions or express a preference for one group of people over another based on how they look, without knowing them.

1 Try it at home! Ask your friends or siblings to draw a scientist. Did they draw a man or a woman? What other features of the picture do you notice? For more see: https://www. calacademy.org/ educators/lessonplans/what-does-ascientist-look-like and to see what real scientists look like, check out: https:// lookslikescience.tumblr. com/archive.

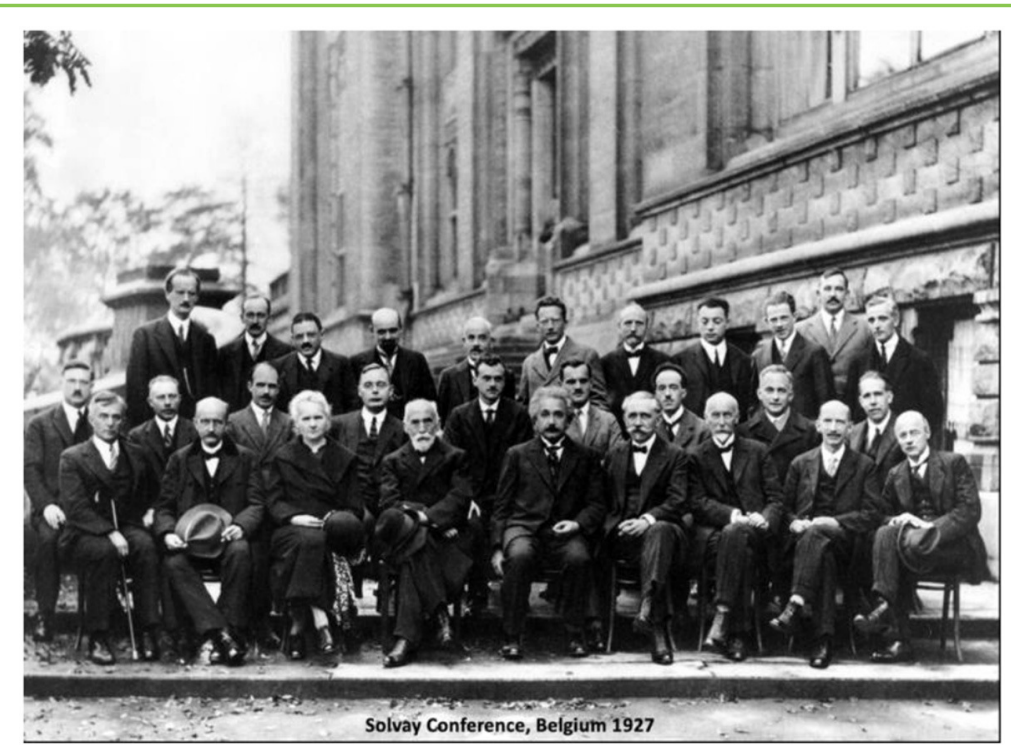

Figure 2

would have been accomplished had women and ethnic minorities been allowed greater access to their ranks. As the historian of science Steven Jay Gould said, "I am, somehow, less interested in the weight and convolutions of Einstein's brain than in the near certainty that people of equal talent have lived and died in cotton fields and sweatshops."

Today, most science departments are more diverse than they were in 1927, but not by much. There is still considerable progress left to make. For example, at Harvard University, $\sim 4$ out of every 5 STEM (science, technology, engineering, and math) faculty members are men. This pattern is reflected in most colleges and universities. Although the explicit discrimination that kept women and minorities out of science in 1927 does not happen as much today, implicit biases, or unconscious stereotypes, still remain and harm a girl's chances of becoming a scientist.

\section{WHAT DOES A SCIENTIST LOOK LIKE?}

In the 1970's, only 1 out of 100 children who were asked to draw a scientist drew a woman [1]. Today, about 30 do $^{1}$ The "Draw a Scientist" test reflects our assumptions of who a scientist is and what a scientist looks like. In another study, children were shown a picture of a man and a woman and then told to "point to the most intelligent one." Four- and 5-years-old tend to choose their own sex, but by age six and beyond girls are more likely to choose the man [2]. Researchers found that girls who believe the stereotype that "boys are smarter than girls" are more likely to avoid games described as "for really smart kids" (Figure 3). Gender stereotypes about intelligence influence children's choices at a heartbreakingly young age. When girls absorb 
Figure 3

Children as young as 6 years old are influenced by the stereotype that men are smarter than women. False stereotypes about intelligence can derail girls' interest in math and science by first grade.

\section{INNOVATION}

Innovation means coming up with a new idea or creative solution to a problem.

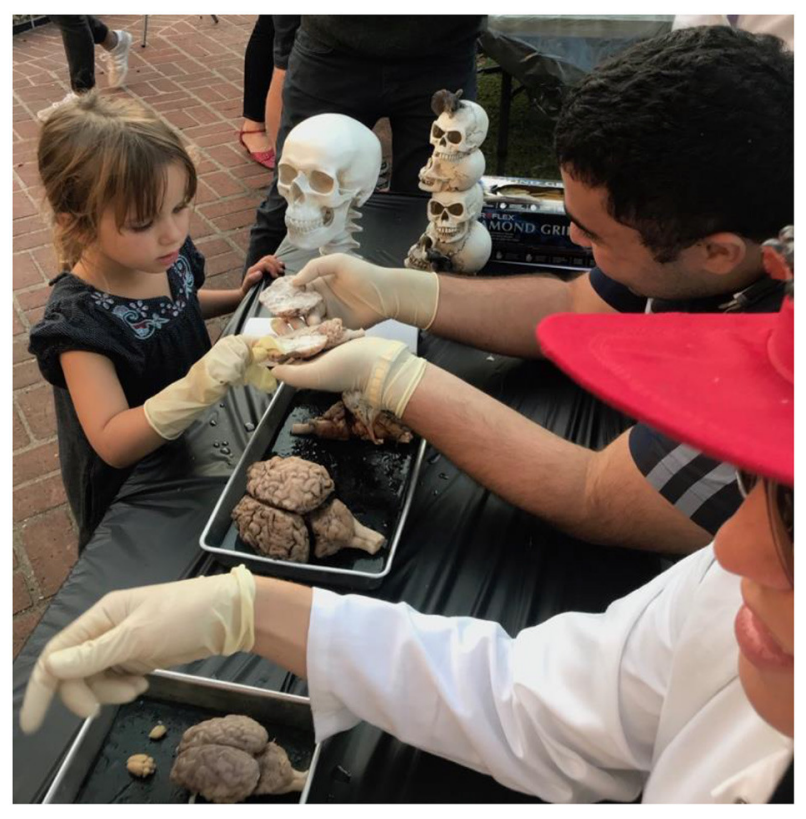

Figure 3

these stereotypes, they are more likely to avoid math and science, while boys' interests in these subjects are encouraged and supported. Over time, these are the kinds of subtle biases that give rise to the under-representation of women in science.

Gender biases in science continue through high-school and college. For example, in one study, researchers mailed fake applications to science teachers who were hiring a lab manager to help with daily activities in the laboratory-a coveted position for young scientists [3]. Lab manager positions often help students get into competitive graduate and medical school programs. In the study, the fake applications were identical except for a single word at the top of the page-the first name of the student was randomly chosen to be male or female. What do you think happened? Science teachers judged male applicants to be more competent and more hirable than identical female applicants. When asked to offer the applicant a starting salary, females were offered $\$ 4,000$ less. These gender biases are not the result of a few teachers with outdated gender attitudes, they are the result of widely held stereotypes about intelligence and reflect who we have in mind when we imagine a scientist.

\section{DIVERSITY DRIVES INNOVATION}

Why does diversity in science matter? Advocating for diversity in science is not just the right thing to do. Diversity in science makes science better. It drives innovation and it can change the very questions that scientists ask. Here are two examples to illustrate this point: 


\section{NEUROSCIENCE}

Neuroscience is the study of the nervous system, which includes our central nervous system (the brain) and peripheral nervous system (all of the nerves that run throughout our body).

\section{COGNITIVE}

Cognitive neuroscience is a branch of neuroscience focused on understanding how our brain gives rise to the mind. How does a network of brain cells produce thoughts, sensations, and feelings?

\section{MENOPAUSE}

Menopause is the time in a woman's life when her period stops. This usually happens a few years after a woman turns 50 . In the years before menopause, hormone levels of estrogen and progesterone in the body declines sharply. Some women experience hot flashes and temporary memory changes due to these hormone changes.
1. Until recently, female animals were excluded from scientific studies, affecting the health of women worldwide. Female scientists discovered the problem and came up with a solution.

Biomedical research relies on animal studies to understand diseases and to test treatments that can save human lives. However, for the last 50 years, these animal studies have been conducted primarily in male animals [4]. That discovery was made by Dr. Annaliese Beery in 2011. She showed that, in neuroscience and other areas of science, researchers tend to exclude female animals from their research. Surprisingly, female animals are even excluded from studies about brain diseases that are more common in women, like Alzheimer's, depression, and anxiety. This bias has compromised the health and safety of women in ways that scientists are just beginning to understand. For example, medicines are more likely to have unintended side effects or lead to serious complications in girls and women, likely because the animal testing did not include females.

The good news is that Dr. Beery's discovery started a national movement. In 2016, our government-in an effort led by a woman named Dr. Janine Clayton-created a new rule to make sure scientific studies include female animals [5]. This is a giant step toward making sure men and women benefit equally from research efforts. Importantly, female scientists played a critical role in this paradigm shift. Dr. Beery noticed something that nobody else noticed. She challenged a research habit that had been passed on for decades and, in doing so, she made a lasting mark on science. Similarly, Dr. Clayton's pioneering efforts to change science policy at the national level made sure that women's health was taken seriously by those performing animal research.

\section{Until recently, brain imaging studies often overlooked topics that} matter for women. Female scientists discovered the problem and came up with a solution.

Gender diversity is also important in cognitive neuroscience. One of the biggest challenges in cognitive neuroscience is understanding how the brain changes as we get older. Neuroscientists want to understand who is on the path to healthy brain aging and who is at risk for dementia. Until recently, most studies of brain aging focused on adults over the age of 65 [6]. This research practice overlooks a critical period in a woman's life-menopause. Menopause is a period of time, usually between ages 45 and 55, when a woman's body stops producing certain hormones and her menstrual cycle stops. Hormones are substances produced by your body that travel through your bloodstream to guide growth, development, behavior, mood, brain function, and more. Many hormones play important roles in brain health, yet until recently few neuroscientists thought about whether men's and women's brains age differently or how menopause 
Figure 4

Girls Inc. is an after-school program for girls ages 6-18. Their mission is to "inspire all girls to be strong, smart, and bold." Learn more at GirlsInc.org.

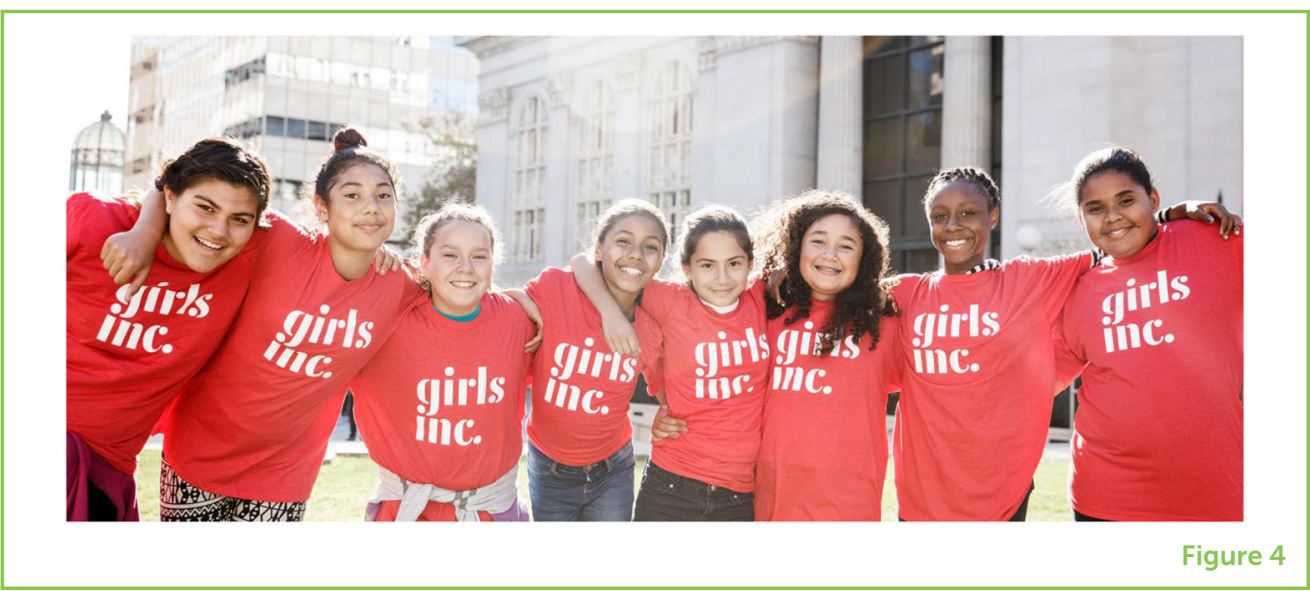

shapes the brain. This oversight is concerning, especially since some age-related diseases, including Alzheimer's, are more common in women. For years, scientists did not realize that the changes in the brain that occur during menopause could hold the secret to why women are at an increased risk for these devastating diseases. As more women enter neuroscience, these questions are starting to be tackled [7].

\section{NEUROSCIENCE NEEDS GIRLS}

Scientists cannot answer questions they do not see. For male neuroscientists studying the aging brain, it is likely that menopause was never "visible." Studying only male animals in the lab did not seem weird until female scientists came along and challenged those old, ingrained assumptions. What are the other questions scientists cannot see because they lack the experience to even imagine them? Science should represent society. We need a diverse pool of neuroscientists who bring radically new perspectives to the table. If history is any evidence, when girls gain a voice, and when they step into positions of power, it transforms science.

I can only hope that when people of future generations look back at a photograph of the most important and influential neuroscientists from the present day, they will see a group of faces that more faithfully represent our social makeup as a whole. If they do, our moonshot may be in reach (Figure 4).

\section{REFERENCES}

1. Chambers, D. W. 1983. Stereotypic images of the scientist: the draw a scientist test. Sci. Educ. 67:255-65.

2. Leslie, S. J., Cimpian, A., Meyer, M., and Freeland, E. 2015. Expectations of brilliance underlie gender distributions across academic disciplines. Science 347:262-5. doi: 10.1126/science.1261375 
3. Moss-Racusin, C. A., Dovidio, J. F., Brescoll, V. L., Graham, M. J., and Handelsman, J. 2012. Science faculty's subtle gender biases favor male students. Proc. Natl. Acad. Sci. U.S.A. 109:16474-9. doi: 10.1073/pnas.1211286109

4. Zucker, I., and Beery, A. K. 2010. Males still dominate animal studies. Nature 465:690. doi: 10.1038/465690a

5. Clayton, J. A., and Collins, F. S. 2014. Policy: NIH to balance sex in cell and animal studies. Nature 509:282-3. doi: 10.1038/509282a

6. Taylor, C. M., Pritschet, L., Yu, S., and Jacobs, E. G. 2019. Applying a women's health lens to the study of the aging brain. Front. Hum. Neurosci. 13:224. doi: 10.3389/fnhum.2019.00224

7. Nebel, R. A., Aggarwal, N. T., Barnes, L. L., Gallagher, A., Goldstein, J. M., Kantarci, K., et al. (2018). Understanding the impact of sex and gender in Alzheimer's disease: a call to action. Alzheimers Dement. 14:1171-83. doi: 10.1016/j.jalz.2018.04.008

SUBMITTED: 15 November 2019; ACCEPTED: 12 March 2020; PUBLISHED ONLINE: 08 April 2020.

EDITED BY: Sabine Kastner, Princeton University, United States

CITATION: Jacobs EG (2020) Why Neuroscience Needs Girls: Gender Diversity Drives Scientific Discovery. Front. Young Minds 8:37. doi: 10.3389/frym.2020.00037

CONFLICT OF INTEREST: The author declares that the research was conducted in the absence of any commercial or financial relationships that could be construed as a potential conflict of interest.

COPYRIGHT @ 2020 Jacobs. This is an open-access article distributed under the terms of the Creative Commons Attribution License (CC BY). The use, distribution or reproduction in other forums is permitted, provided the original author(s) and the copyright owner(s) are credited and that the original publication in this journal is cited, in accordance with accepted academic practice. No use, distribution or reproduction is permitted which does not comply with these terms.

\section{YOUNG REVIEWERS}

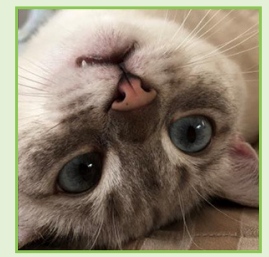

\section{CASSIDY, AGE: 13}

Cassidy's dream is to be an actress. She has taken musical theater for 2 years and plays the flute. She has a 2 years old cat named Violet who enjoys cuddling and pouncing on toys. Cassidy dreams of attending Harvard University.

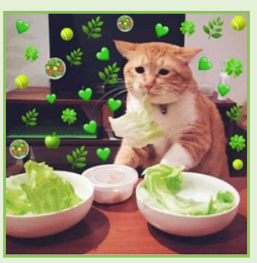

\section{EMILY, AGE: 13}

Emily is an artistic soul who is into anime, cooking, and musical theater. They use they/them pronouns and are very proud to be pansexual. They aspire to be an artist when they grow up and hope to 1 day to live up to that dream. 

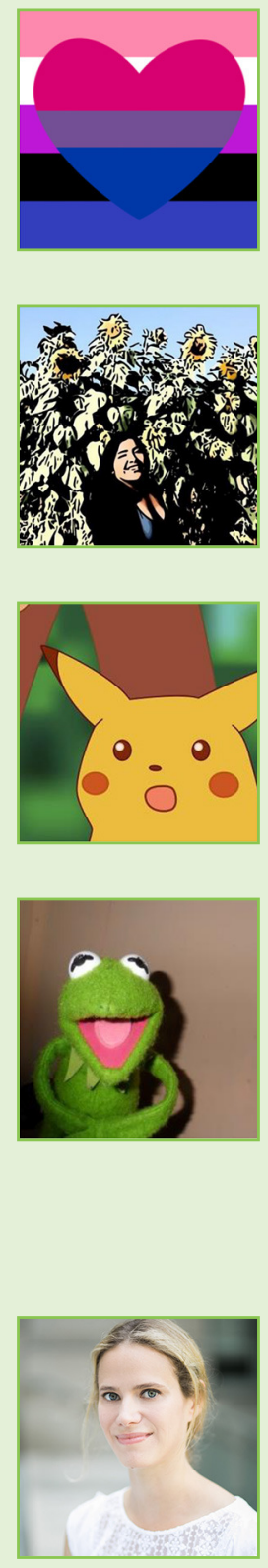

\section{LEE, AGE: 18}

Lee is a senior at Santa Barbara High School and uses they/them pronouns. They are a passionate advocate for the LGBTQ+ Community. Lee enjoys reading, writing, drawing, and also loves science. They dream of getting a doctorate in linguistics or Psychology.

\section{SARAHI, AGE: 16}

Sarahi is a junior in High School. Her pronouns are she/her/hers/ella. She loves art and being able creates new things. She is a proud Chicana (Mexican-American) and plans to contribute back to her community by encouraging younger Chicana youth to continue their education.

\section{SAWYER, AGE: 13}

Sawyer is an artist who carries her drawings everywhere she goes. She is a Santa Barbara local who is taking French and plans to major in English, writing, and/or social sciences. She is part of the Pride community and is very open about her identity.

\section{ZAHRA, AGE: 13}

Zahra is an eighth grader who uses she/her/hers pronouns. She is passionate about musical theater and is currently a lead in her school play. She loves shopping and spending time with her friends. She aspires to be in more musical plays in the future.

\section{AUTHOR}

\section{EMILY G. JACOBS}

Emily is a neuroscience professor at the University of California, Santa Barbara. Before that she was an instructor at Harvard Medical School, a graduate student at UC Berkeley, and an undergraduate student at Smith College. Her laboratory uses brain imaging tools to study the brain and how it changes over days, weeks, months, and years. The Jacobs Lab is particularly interested in how the brain adapts as women transition to menopause. In addition to research, Emily advocates for diversity in science at the national and international levels. The Jacobs Lab regularly partners with K-12 groups to advance girls' representation in STEM, work that was featured in the book "STEMinists: The Lifework of 12 Women Scientists and Engineers." Emily's husband, Michael, is also a neuroscientist and they are proud parents to their daughter Elowen (age 6). *emily.jacobs@psych.ucsb.edu 